NASZA DERMATOLOGIA Online OUR DERMATOLOGY Online

Source of Support: Nil

Competing Interests: None declared

\section{DERMATOLOGY IN THE INTENSIVE CARE UNIT}

\author{
Uwe Wollina ${ }^{1}$, Andreas Nowak ${ }^{2}$
}

${ }^{I}$ Repartment of Dermatology and Allergology Academic Teaching Hospital Dresden-Friedrichstadt, Friedrichstrasse 41, 01067 Dresden, Germany

${ }^{2}$ Department of Anaesthesiology \& Intensive Medicine, Emergency Medicine \& Pain Management, Academic Teaching Hospital Dresden-Friedrichstadt, Friedrichstrasse 41, 01067 Dresden, Germany

Corresponding author: Prof. Dr. Uwe Wollina Dr. Andreas Nowak

wollina-uw@khdf.de nowak-an@khdf.de

\begin{abstract}
Introduction: The intensive care unit (ICU) represents a special environment for patients. We analyzed patients in the ICU/ high care unit (HCU) with respect to dermatology counselling and skin problems.

Setting: Academic Teaching Hospital over a 10 month period.

Material and Methods: The total number of patients of the ICU was 1,208 with a mean stay of 4.1 days. In the HCU the mean stay was 16 days. Diagnosis leading to admission were analyzed. All files of dermatological counselling were evaluated in detail.

Results: Fifty-five patients with dermatologic problems were identified: 19 women and 26 males. The age ranged from 22 to 90 years of life (mean \pm standard deviation: $67.2 \pm 17.4$ years). The total number of consultations were 85 . The range of repeated dermatological consultation ranged from two to ten. The major reasons were skin and soft tissue infections, adverse drug reactions, chronic wounds including pressure sores and skin irritation or dermatitis. Pre-existing skin conditions may complicate the treatment and care during ICU/HCU stay.

Conclusions: A tight collaboration between of the medical staff of ICU/HCU and dermatology department will ensure a rapid diagnosis and treatment of various skin conditions in the ICU, without increasing the costs significantly. Interdisciplinary education of nursing staff contributes to improved skin care in the ICU/HCU and helps to prevent acute skin failure.
\end{abstract}

Key words: Intensive Care Unit; dermatological counselling; skin diseases

\section{Introduction}

Patients in intensive care units (ICU) represent a proportion of patients with most complex medical issues. Counselling of other specialities is a common procedure to avoid delay of diagnosis and specific treatment. Surprisingly not much has been published on interaction with and the role of dermatology in such a setting although skin diseases are quite common in the general population [1]. Data from burn centres suggest that an intense teamwork with dermatologists seem to be favourable for patients [2].

Skin diseases itself may lead to ICU admission in case of emergencies like severe adverse drug reactions including Stevens-Johnson syndrome [3], drug reactions with eosinophilia and systemic symptoms (DRESS) [4], toxic epidermal necrosis [5], serum sickness-like syndrome [6]. The incidence of Stevens-Johnson syndrome and toxic epidermal necrolysis has been calculated as high as 1.89 per million inhabitants per year in western Germany and Berlin [7]. A survey from Britain identified the following big three dermatological admissions: infectious diseases, cutaneous malignancies and acute skin failure. The mortality rate for patients with dermatologic diseases in ICU was estimated as high as $27.5 \%$, with $39.6 \%$ who died before ultimate discharge from the hospital [8].

In this study we would like to analyze skin problems in ICU patients in an Academic Teaching Hospital in the south-east of Germany. We will focus on those skin problems that need a dermatological counselling during the patient's stay in the ICU. We hope that such an analysis will better define the necessary for an optimal patient care and also that we appreciate the importance of team work which is vital in such an environment to avoid unnecessary misdiagnosis and treatments.

\section{Material and Methods}

Patients: We analyzed patients in the Intensive Care Unit (ICU) of our hospital treated from January to October 2010 including dermatological counselling. 
The average annual number of dermatologic consultations in the whole Academic Teaching Hospital is 2,000 to 2,500. The patients were analyzed for diagnosis, treatment and diagnostics resulting from the dermatologic consultations.

\section{Results}

The total number of patients of the ICU was 1,208 with a median stay of 4.1 days. The Department of Anaesthesiology \& Intensive Medicine, Emergency Medicine and Pain Management runs a specialized high care unit (HCU) with 16 places for assisted ventilation among other facilities. Table I summarized diagnoses for admission in this ICU.

\begin{tabular}{|c|c|}
\hline Diagnosis & $\mathbf{N}$ \\
\hline Intracerebral bleeding & 16 \\
\hline Acute haemorrhagic anaemia & 8 \\
\hline Respiratory insufficiency & 8 \\
\hline Pancreatitis & 5 \\
\hline Polytrauma & 4 \\
\hline Peritonitis & 3 \\
\hline Pneumonia & 3 \\
\hline Fractures, spine & 3 \\
\hline Renal insufficiency & 2 \\
\hline Urosepsis & 2 \\
\hline Ileus & 2 \\
\hline Cardiac insufficiency & 2 \\
\hline Abscess, intraspinal & 1 \\
\hline Abscess, lower leg & 1 \\
\hline Acute cholecystitis & 1 \\
\hline Acute enteric ischaemia & 1 \\
\hline Acute ischaemic enterititis & 1 \\
\hline Acute mastoiditis & 1 \\
\hline Anaphylaxis, drug-induced & 1 \\
\hline Colon diverticulitis with abscess formation & 1 \\
\hline Colon necrosis & 1 \\
\hline Colon torsion & 1 \\
\hline Collum phlegmonia & 1 \\
\hline Discitis, lumbar & 1 \\
\hline Endocarditis & 1 \\
\hline Empyema, knee joint & 1 \\
\hline Gut perforation & 1 \\
\hline Haemato-pneumothorax & 1 \\
\hline Hypopharyngeal malignancy & 1 \\
\hline Infection due to joint prothesis & 1 \\
\hline Larynx oedema & 1 \\
\hline Noninfectious colitis & 1 \\
\hline Oesophageal resection & 1 \\
\hline Perforated aortal aneurysm & 1 \\
\hline Reanimation & 1 \\
\hline Rhabdomyolysis & 1 \\
\hline Shot gun injury, lung & 1 \\
\hline Thoracic abscess & 1 \\
\hline Tracheostoma & 1 \\
\hline
\end{tabular}


The median time of stay for HCU patients was longer compared to the general ICU population, i.e. 16 days (standard deviation 35.4 Days). Among the HCU patients 47 patients suffered from sepsis, 12 patients died. The median time of assisted ventilation was 288 hours (standard deviation 783 hours). In the following we will focus on the HCU facility.

Fifty-five patients with dermatologic problems were identified: 19 women and 26 males. The age ranged from 22 to 90 years of life (mean \pm standard deviation: $67.2 \pm 17.4$ years). The total number of consultations was 85 . The range of repeated dermatologic consultation ranged from two to ten.

Two cases were excluded from further analysis: one patient had died before the bedside consultation was possible and another patient had no dermatologic symptoms at the time of consultation.

A major problem was communicating with the patients. This was due to patients on respirators or had impaired hearing function or dementia and others. The following analysis groups various patients into different categories of skin problems. Each patient could be further classified in more than one category.

Infestations and infections: Viral infections were most common $(\mathrm{n}=8)$ including generalized and localized herpes zoster and herpes simplex. The usual treatment for herpes zoster was systemic acyclovir and astringent topical lotions. None of the ICU patients were hospitalized for the viral infections but they still had an impact on treatment and costs. Although septicaemia is an important indication for HCU treatment it was not a cause for the dermatological counselling.

However, some septicaemic patients were seen by the dermatologist for secondary problems such as skin irritation, adverse drug reactions, oedema and soft tissue infections.

Bacterial infections seen by the dermatologist in the HCU included five patients with erysipelas $(n=2)$, phlegmonia $(n=1)$, abscess formation $(n=2)$, and there was a single case of suspected gas brand infection (Fig. 1).

The recommended treatment was either surgical, systemic antibiotics or a combination of both. Furthermore, bacterial infections can cause significant morbidity and mortality in

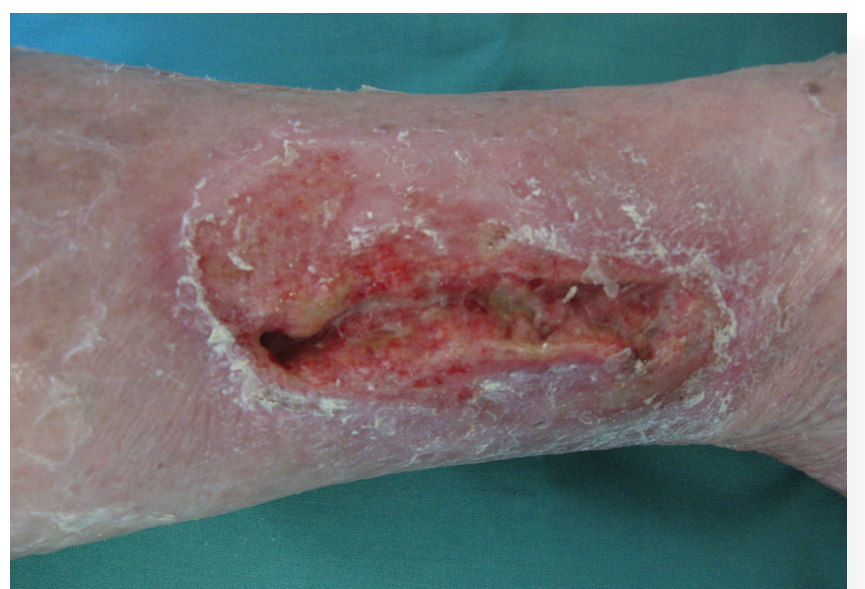

Figure 2. Atypical phlegmonia (no fever, very limited redness, limited pain, but general malaise) in a patient with treatment with anti-tumour-necrosis-factor alpha therapy

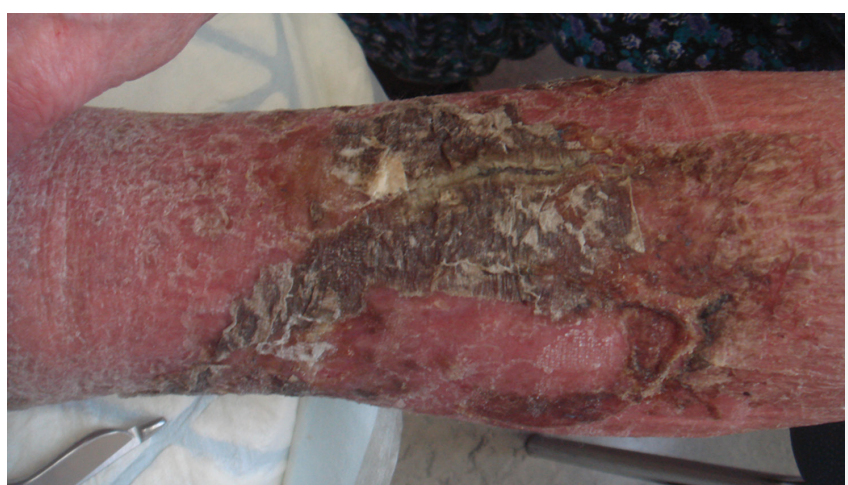

Figure 1. Vaselinoderma in chronic venous insufficiency, mimicking infection and erysipelas. There is no need for antibiotics but cleansing and skin care

the HCU. They are a major factor for increasing the costs by using newer classes of antibiotics due to bacterial resistance, instead of classical antibiotics which are cheaper.

Infestation with head lice was seen once during the observation period.

Skin irritation: The major age group was in their 7th and 8th decade of life. Xerosis cutis is often seen that can aggravate in an environment such as HCU, of which the major clinical symptoms are pruritus, excoriations, desquamation and redness are major clinical symptoms. The diagnosis of asteatotic eczema was confirmed in five patients (Fig. 2, 3 ). Skin care and treatment with emollients and sometimes topical corticosteroids were recommended.

One particular problem with obese patients in HCU was the development of intertrigo $(n=2)$. The disease can be aggravated with larger ulcerations which could lead to bacterial and mycotic infections. The topical treatment in these cases is more meticulous therefore requiring more attention.

Patients with sensitive skin can develop irritant contact dermatitis due to skin care products, wound dressings and disinfectants. We have seen one patient who developed contact dermatitis due to plasters.

Wounds: The dermatological consultation for problems with chronic wounds plays a significant role in the HCU $(n=8)$.

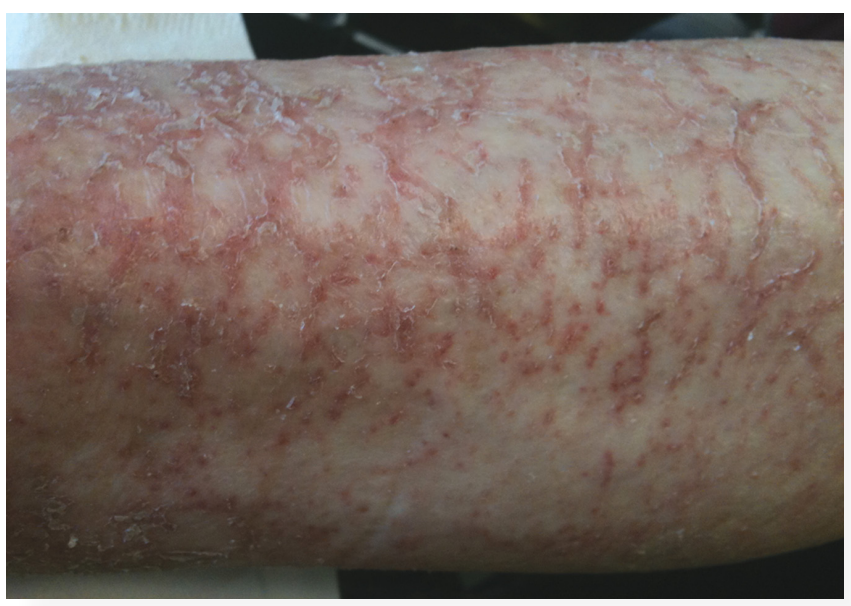

Figure 3. Asteatotic eczema (69-year-old male patient). This is a complex condition caused by intrinsic ageing, inadequate skin care, can be worsened by statins 
These wounds may have developed before hospital admission or during the stay in the HCU. We did not come across any major wounds developing during the HCU stay. Some patients, however, suffered from large pressure sores $(n=1)$. Minor pressure sores (small ulcers mainly on the feet, grade I-II) were also seen as a result of prolonged immobilization, i.e. during respirator treatment after septicaemia or shock therapy $(\mathrm{n}=3)$.

Patients with leg ulcers were examined by the dermatologist for further advice of good ulcer care $(n=2)$.

Sometimes post surgery wound problems develop, when the patient needs to be treated in the HCU for other severe conditions. There was one patient with limited skin flap necrosis and there was only one patient for follow-up after mesh-graft transplantation.

Adverse drug reactions: The major part of adverse drug reactions in the HCU consists of acute rash with macular, papular or urticarial lesions. We saw seven patients with drug rash ranging from very mild to life-threatening allergic shock. In all of these patients but one, systemic antibiotics was a suspected cause (Fig. 4). One patient had a drug rash after non-steroidal anti-inflammatory drug, while another patient developed steroid-acne due to systemic corticosteroid therapy. Although confirmation of suspected medical drugs by in vivo and in vitro allergy tests is most important, this cannot be investigated during stay in the HCU. In most cases topical corticosteroids, systemic antihistamines and cessation

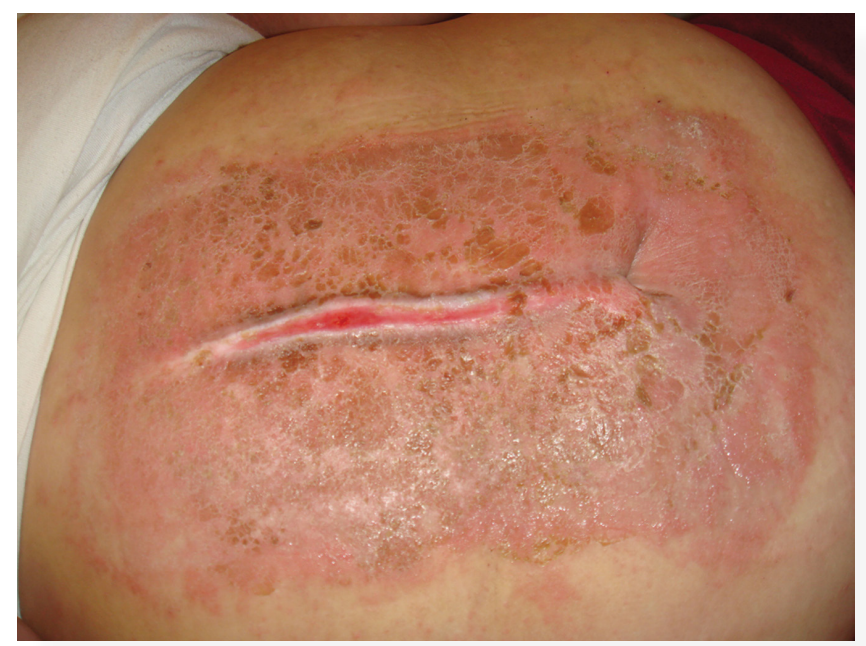

Figure 4. Subacute irritant contact dermatitis with sharp borders due to glue in wound dressing

\section{Discussion}

The ICU/HCU is a special environment for critically ill patients leading to various skin conditions which could be detrimental to the health of the patient due to immobility, sweating and decreased perfusion. Non-invasive measurements of transepidermal water loss (TEWL) and skin surface $\mathrm{pH}$, however, did not show generally a significant deterioration of skin barrier function in ICU patients [9].

Nevertheless asteatotic eczema and other irritant skin conditions were quite common among our mostly elderly patients. There is a need for improved skin care with moisturizers and avoidance of irritants. Untreated eczema (dermatitis) can become a cause of an acute skin failure as well as adverse drug reactions, bullous diseases and others. Since of the suspected drug therapy leads to complete remission, sometimes systemic corticosteroids and other measures may be needed. It is most important to mention the suspected drug allergy in all patient files and reports (allergy passport) to prevent a second exposure with the possibility of a fatal outcome. It was reported that irritant contact dermatitis due to electrodes or wound dressings can also occur (Fig. 5).

Pre-existing skin problems: Some patients were submitted to $\mathrm{HCU}$ with a pre-existing chronic skin disease $(n=4)$. Whereas atopic dermatitis and psoriasis could be expected since they are common, orphan diseases may need complex procedures and treatment and further dermatological consultations may become necessary. We have seen one patient with bullous pemphigoid who needed 10 consultations during his stay at HCU. Other skin diseases which were included were psoriasis $(n=2)$ and a basal cell carcinoma patient.

Diagnostics: Most cases could be confirmed by clinical examination with or without dermoscopy. Diagnostic excision was recommended in one patient in case treatment failed. Mycologic culture of skin scraps was suggested in two cases.

Additional costs: Early dermatological counselling will not have a negative impact on future costs of diagnosis or treatment but it is capable of preventing the increase of costs that arise after delayed diagnosis of severe skin conditions and diseases.

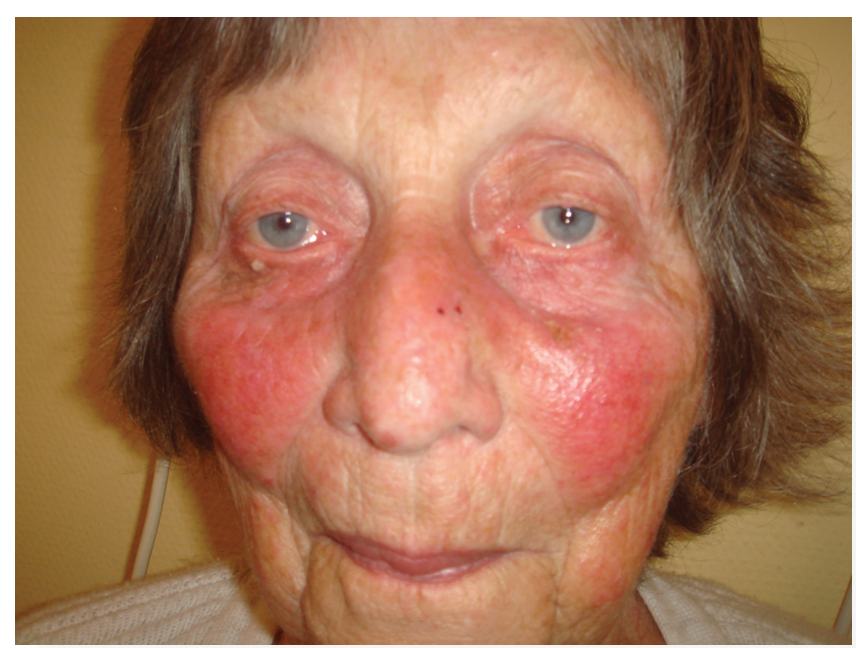

Figure 5. Butterfly-like rash caused by ampicillin

many of our ICU/HCU patients were elderly polypragmatic drug therapy is a risk for adverse drug reactions [10].

One of the most severe presentations of identified skin conditions in ICU is the risk of acute skin failure. Acute skin failure is defined as loss of temperature control with subsequent inability to maintain the core body temperature, loss of fluid, electrolytes and protein, and disruption of skin barrier function markedly increasing the risk of severe infections [11].

In such patients TEWL raises from $400 \mathrm{ml} /$ day to $>1000$ $\mathrm{ml} / \mathrm{d}$. TEWL is highest during scaling of skin, e.g. after toxic exanthema. Electrolyte imbalance (low sodium and high potassium) is often accompanied by hypophosphataemia what aggravates insulin resistance [12]. 
There is a loss of nutrients in particular by scaling. Peripheral oedema is commonly seen in long-standing cases due to hypoalbuminaemia, associated cardiac failure and inflammation form primary skin diseases. There is increased capillary leakage and shift of fluid to extracellular space. In erythroderma increased levels of vascular permeability factor and vascular endothelial growth factor have been detected in circulation [13].

Acute skin failure can give raise to pulmonary, immunological and vascular complications.

Therefore monitoring of these patients and care in an interdisciplinary team with well-skilled nurses is a must. Regular removal of crusts and skin cleansing, barrier-nursing and use of emollients to recover skin barrier function are recommended [14].

Skin and soft tissue infections (SSTI) can contribute to morbidity and mortality in ICU. In a population-based study from Taiwan covering almost 150,000 patients one third of ICU patients suffered from SSTI had also nonSSTI which where responsible for ICU admission. The three most common groups of SSTI were „other cellulitis or abscess", „decubitus ulcer” and ,post-operation wound infection"; and they accounted for $76.5 \%$ of all hospitalized cases and for $72.9 \%$ of ICU ones, respectively. In addition, „infection caused by vascular device/implant”, ,gangrene” and ,necrotizing fasciitis" comprised another $24.3 \%$ of the ICU cases. Among the six SSTI, the ICU admission rates were the highest in ,necrotizing fasciitis” (23.8\%), followed by „decubitus ulcer” $(22.8 \%)$, ,infection due to vascular device/implant" (21.2\%), ,post-operation wound infection" (17.8\%), ,gangrene” (15.4\%) and „other cellulitis/abscess" $(3.8 \%)$, respectively [14]. Others reported fatal SSTI in ICU in up to $59.1 \%$ reflecting the different social and ethnic background and triage policy [15].

An observational, cross-sectional cohort study was conducted in the United States in 2008 and 2009. The overall prevalence and facility-acquired pressure sore rates were $13.5 \%$ and $6 \%(2008, \mathrm{n}=90,398)$ and 12.3 and $5 \%(2009, \mathrm{n}$ $=92,408)$, respectively. In 2008 and 2009, overall prevalence rates were highest in long-term acute care (22\%). Facilityacquired rates were highest in adult ICUs and ranged from $9.2 \%$ to $12.1 \%$ in 2008 and from $8.8 \%$ to $10.3 \%$ in 2009 [16]. An analysis in a tertiary hospital with a pressure sore rate of $12 \%$ tried to define factors related to pressure sore development. Multivariate analysis showed that "emergency ICU/high care unit (HCU) patients" and "infrequent turning" were related to pressure ulcer development. Patients with pressure ulcers experienced significantly fewer turns and repositionings $(\mathrm{OR}=0.452,95 \% \mathrm{CI}$ : 0.212-0.966], $\mathrm{p}<0.05$. Fewer pressure ulcers developed in scheduled ICU/HCU patients than in emergency ICU/HCU patients $(\mathrm{OR}=0.041$ [95\% CI: 0.004-0.470], p < 0.01) [17]. This can explain why patients with prolonged assisted ventilation have a higher risk of pressure sore development [18]. Other risk factors for the development of pressure sores include age, length of stay, mobility, friction/shear, norepinephrine infusion, and cardiovascular disease explained a major part of the variance in pressure ulcers [19].

Skin diseases can markedly increase the time needed for treatment and care. They may also prolong the stay in ICU/HCU, in particular SSTI [8]. The control of skin diseases during ICU stay is related to the implementation of an interventional hygiene plan with standards of nursing, bathing, use of beds, skin care, and prevention of incontinence-related dermatitis [20]. In a recent report from a pediatric ICU the majority of skin problems resulted from an underlying illness responsible for admission to the ICU, e.g. infection, vasculitis, or adverse drug reaction. In 15 of 42 cases dermatological problems were related to the ICU care regimen, such as adverse drug reactions, pressure sores or catheter complications [21]. Although skin diseases can be a factor increasing the risk of mortality in the ICU, fortunately we did not observe any case in our analysis. We conclude that the intense cooperation between the staff and dermatology department in the management of the critically ill patients with skin problems is a necessity.

Another important issue is the interdisciplinary education of the nursing staff which has been practised in our hospital since many years. One of the topics in the continuous education of the prevention and treatment of chronic wounds like pressure sores.

Furthermore, in order to improve the patient care, the dermatology department should be strictly involved in this continous medical education for both the doctors and nurses. On the other hand, there is a need for better understanding the principles of intensive care by counselling dermatologists to improve further communication and select appropriate treatment.

\section{Acknowledgements}

We wish to acknowledge the help of Mrs. Hertz taking clinical photographs.

\section{REFERENCES}

1. Dunnill MG, Handfield-Jones SE, Treacher D, McGibbon DH: Dermatology in the intensive care unit. Br J Dermatol. 1995;132:226-35.

2. Barillo DJ, Goodwin CW: Dermatologists and the burn center. Dermatol Clin. 1999;17:61-75.

3. Wetter DA, Camilleri MJ: Clinical, etiologic, and histopathologic features of Stevens-Johnson syndrome during an 8-year period at Mayo Clinic. Mayo Clin Proc. 2010;85:131-8.

4. Eshik M, Allanore L, Musette P, Mipied B, Grange A, Guillaume $\mathrm{J}-\mathrm{C}$, et al: Twelve-year analysis of severe cases of drug reaction with eosinophilia and systemic symptoms. A cause of unpredictable multiorgan failure. Arch Dermatol. 2009;145:67-72.

5. Gerdts B, Vloemans AF, Kreis RW: Toxic epidermal necrolysis: 15 years' experience in a Dutch burns centre. J Eur Acad Dermatol Venereol. 2007;21:781-8.

6. Wolf R, Orion E, Marcos B, Matz H: Life-threatening acute adverse cutaneous drug reactions. Clin Dermatol. 2005;23:171-81.

7. Rzany B, Mockenhaupt M, Baur S, Schröder W, Stocker U, Mueller J, et al: Epidemiology of erythema exsudativum multiforme majus, Stevens-Johnson syndrome, and toxic epidermal necrolysis in Germany (1990-1992): structure and results of a populationbased registry. J Clin Epidemiol. 1996;49:769-73.

8. George SM, Harrison DA, Welch CA, Nolan KM, Friedmann PS: Dermatological conditions in intensive care: a secondary analysis of the Intensive Care National Audit and Research Centre (ICNARC) Case Mix Programme database. Crit Care. 2008;12(Suppl 1):S1. 9. Fischer M, Donath C, Radke J, Marsch WC, Soukup J: Skin function parameters in intensive-care patients. Skin Res Technol. 2005;11:268-71. 
10. Trivalle C, Cartier T, Verny C, Mathieu A-M, Davrinche P, Agostini $\mathrm{H}$, et al:. Identifying and preventing adverse drug reactions in elderly hospitalised patients: A randomised trial of a program to reduce adverse drug effects. J Nutr Health Aging. 2010;14:57-61. 11. Inamadar AC, Palit A: Acute skin failure: Concepts, causes, consequences and care. Indian J Dermatol Venereol Leprol. 2005; $71: 379-85$.

12. Rojeau JC, Revuz J: Intensive care in dermatology. In: Champion RH, Pye RJ (eds): Recent Advances in Dermatology. Edinburgh: Churchill-Livingstone; 1990: p. 85-99.

13. Creamer D, Allen MH, Groves RW, Barker JN: Circulating vascular permeability factor/ vascular endothelial growth factor in erythroderma. Lancet. 1996;348:1101.

14. Elias PM, Feingold KR: Does the tail wag the dog? Role of the barrier in the pathogenesis of inflammatory dermatoses and therapeutic implications. Arch Dermatol. 2001;137:1079-81.

15. Shen HN, Lu CL: Skin and soft tissue infections in hospitalized and critically ill patients: a nationwide population-based study. BMC Infect Dis. 2010;10:151.
16. VanGilder C, Amlung S, Harrison P, Meyer S: Results of the 2008-2009 International Pressure Ulcer Prevalence Survey and a 3-year, acute care, unit-specific analysis. Ostomy Wound Manage. 2009;55:39-45.

17. Kaitani T, Tokunaga K, Matsui N, Sanada H: Risk factors related to the development of pressure ulcers in the critical care setting. J Clin Nurs. 2010;19:414-21.

18. Manzano F, Navarro MJ, Roldán D, Moral MA, Leyva I, Guerrero C, et al: Pressure ulcer incidence and risk factors in ventilated intensive care patients. J Crit Care. 2010;25:469-76.

19. Cox J: Predictors of pressure ulcers in adult critical care patients. Am J Crit Care. 2011;20:364-75.

20. Eigsti JE: Innovative solutions: beds, baths, and bottoms: a quality improvement initiative to standardize use of beds, bathing techniques, and skin care in a general critical-care unit. Dimens Crit Care Nurs. 2011;30:169-76.

21. Sillevis Smitt JH, van Woensel JB, Bos AP: Skin lesions in children admitted to the paediatric intensive care unit: an observational study. Eur J Pediatr. 2011;170:1263-5. 